\title{
Investigating the Impact of Income, Belief and Culture on Road Safety
}

\author{
Faisal Magableh ${ }^{1}$, Jamal Al Matawah ${ }^{2,}$, Brian Freeman ${ }^{3}$ \\ ${ }^{1}$ Transport and Road Safety Research Center, University of New South Wales, Sydney, Australia \\ ${ }^{2}$ Civil Engineering Department, College of Technological Studies, Kuwait (PAAET), Al Shuwaikh, Kuwait \\ ${ }^{3}$ Lakes Software, Waterloo, Canada
}

Email address:

magableh@gmail.com (F. Magableh),jamaln1@hotmail.com (J. Al Matawah), brianfree67@hotmail.com (B. Freeman)

${ }^{*}$ Corresponding author

\section{To cite this article:}

Faisal Magableh, Jamal Al Matawah, Brian Freeman. Investigating the Impact of Income, Belief and Culture on Road Safety. American Journal of Traffic and Transportation Engineering. Vol. 6, No. 3, 2021, pp. 81-94. doi: 10.11648/j.ajtte.20210603.13

Received: May 24, 2021; Accepted: June 15, 2021; Published: June 23, 2021

\begin{abstract}
People's lives are influenced by their socio-economic, culture, and belief as they shape their behaviors and lifestyles. Belief and culture of people in different countries may profoundly affect their perception towards road safety. Lifestyle controls the perception of people regards road safety. Culture is the navigation system that guides people through their daily life when they enact their lifestyle within their cultural context. The overall aim of this research is to investigate whether there is any relationship between road safety and the income, culture, and beliefs of people. Data from 175 countries that includes income, beliefs and cultures of different countries was used in cross-cultural and cross belief comparisons to obtain a better understanding of the effect of each factor on road safety. The findings showed a remarkable difference in road safety between high, middle, and low-income countries. Different cultures and religions showed different levels of road safety. Whether or not road safety is dependent on these factors requires more studying and analysis. The results show no relationship between road safety and culture or religious beliefs. A noticeable relationship was found between income and road safety level. Countries where traffic regulations are more stringently enforced were found to have the best road safety levels. The outcome of the study can be beneficial for policy and decision-makers when designing road safety strategies and awareness campaigns.
\end{abstract}

Keywords: Road Safety, Culture, Religion, Belief, Income Level, Risk Perception

\section{Introduction}

The World Health Organization (WHO) estimates over 1.35 million road fatalities took place in 2017 [1] or approximately 3,700 road fatalities every day. These figures are expected to climb as 104 countries showed an increase in fatalities from previous years while only 48 countries reported a decrease in road fatalities. The countries with decreasing fatality rates include 25 high-income countries and 23 middle-income countries. No low-income countries reported decreased road fatalities [1]. Over $93 \%$ of the world's road fatalities take place in low and middle-income countries. These countries account for $60 \%$ of the world's vehicles and $85 \%$ of the world's population in 2017 [1]. Developing countries suffer the highest fatalities/10K vehicles, especially among young people. This high fatality rate has sparked questions concerning the root causes behind this road trauma.

The road is a common space where individuals from different social backgrounds meet and interact with other road users within their cultural framework [2] and social influences [3]. The social context of each driver acts as a navigation system [4]. The driving style of people is influenced by their lifestyle and culture [5]. Driving has been correlated with certain socio-demographic, personal and motivational factors $[6,7]$ and is thought to be shaped by intrinsic factors (e.g., sex, age, and cognitive bias) and extrinsic factors (e.g., cultural and social context) [8]. Drivers who have their religion or culture as their salient lifestyle traits were found to have less crash risk implying that both religious and culture-oriented drivers are less likely to be involved in crashes $[9,10]$. 
Humans execute their actions within their social context where violations require social approval, and errors are dependent on the character of the individual and their cognitive processing of information [8]. Some behaviors like hostile aggression, (e. g. verbal abuse) and instrumental aggression (e.g., tailgating and pushing) appear on roads if they are acceptable culture norms $[11,12]$. Certain cultural aspects may give rise to certain driving styles. For example, the contemporary concept of time management and efficiency may lead to speeding, tailgating, and aggressive driving styles that individuals learn while growing up and establishing their behavioral patterns in their society. Risk culture may arise from an accumulation of unsafe behavior patterns in certain groups, such groups with a critical impact on road safety may be subcultures of specific races, gender or ages [13, 14]. Some cultures and ethnic origins were found to take more road risks than other groups. For example, Hispanic males were shown to have a higher proportion of fatalities than any other ethnic group [14].

Social culture and beliefs play an important role in road safety and crash prevention among people [15-18]. Religion plays a powerful role in the daily lives of followers and have significant impacts on their behavior. It provides a set of rules that govern people's lives and relations. Religious beliefs may sometimes engender a kind of fatalism and/or sense of automatic forgiveness. Fatalism is the belief that a person's future is predetermined and that he or she is powerless to change any aspect of the course of events. In road safety, fatalism implies that no matter what people do, crashes and casualties will occur [19]. Fatalism was reported to impact the perception of people towards safety [20].

Fatalism was found to influence Buddhists' reactions to and attribution of road crashes [21]. Fatalism and mysticism (prayers, visits to fortune tellers or marabouts, astrology, various sacrifices, protective medallions, such as the St. Christopher medal in the Western world) may become part of driver's behavior when traffic rules are set in a way that leaves no space for drivers to have their own interpretation of road safety situations [22]. Fatalism was found in both developed and developing countries; however, the level of importance may differ from one country or culture to another [18]. Fatalism was found to be linked to religions (like Buddhism) in Thailand and Canada [21, 23]. Islam in Indonesia and Pakistan $[16,24]$ and Christianity in Canada [23].

This research will investigate whether there any relationships between the income of people, their beliefs, and their culture from one side and the level of road safety represented by numbers of fatalities per 100,000 population from the other side. We seek to investigate the following questions:

1. Does per capita income of a country have an effect on the number of road fatalities in that country?

2. What impact do the beliefs of people in a country or region have on the level of road safety in that area?
3. Does the culture of people influence their compliance with road rules and the numbers of road fatalities?

\section{Methodology}

This study attempts to identify possible links between road fatalities, national income, culture, and beliefs. Data on road deaths, population, income levels, and vehicle numbers from 175 countries around the world were retrieved from UN sources. For the purpose of this study, these countries are sorted according to their income, the religious belief of most country's people and relevant cultures in each country.

The studied countries were divided into low, middle and high-income sub-groups according to the UN classification [1].

We further divided countries into eight sub-regions and treated each sub-region as distinct cultures. Individual cultures were based on common factors within the country rather than an exact description of different cultures around the world. These common factors include language, traditions, ethnic origin similarity, geographic location, history, political orientations, and beliefs. Defined cultures included African, Chinese, East European and the former Soviet Union (Eastern), Indian, Middle Eastern and North African (MENA), North American and Western European (Western), Latin America and the Caribbean (Latino) and the South-East Asian (Asian) cultures.

Most countries have a mix of religions and cultures. For the purpose of this study, each country was assigned the majority religion based on recent census statistics [25]. Religious classifications included predominantly Buddhist countries (Buddhists), predominantly Jewish or Christian countries (Christians), predominantly Hindu countries (Hindus), predominantly Muslim countries (Muslims), predominantly Non-religious countries (Non-religious) and predominantly traditional and indigenous beliefs countries (Indigenous). Traditional and indigenous beliefs are based on local traditions and dogmas of the people.

Twenty-eight (28) countries with populations of less than 1 million were ignored, leaving 147 countries for analysis. Countries with small populations were excluded because they would have skewed results without providing the necessary sampling variance.

Due to the overlapping of different variables with each other, the research studied each factor separately before studying evaluating combined effects.

\section{Results}

\subsection{The Impact of Income}

Country income classification used in the study is shown in Figure 1. Most countries are classified as Middle Income with High Income countries mostly in North America and Europe. Most of the Low-Income countries show in the map are in Africa. 


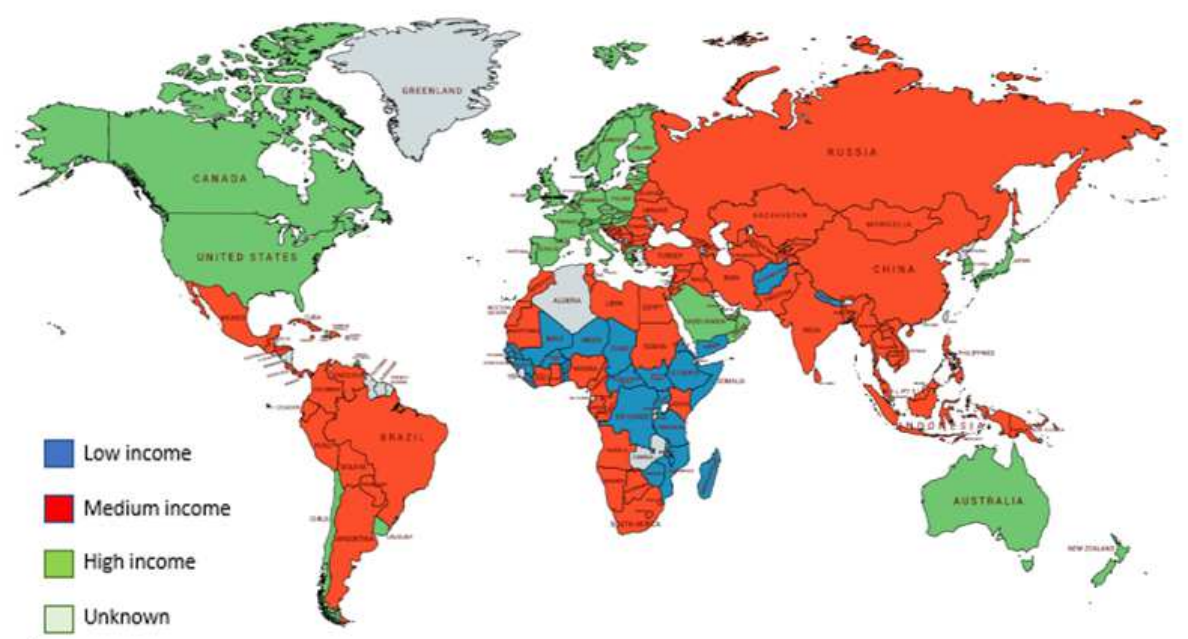

Figure 1. World income map according to the classification of this study.

The distribution between population and registered vehicles by incomes is shown in Figure 2. The different colored clusters and logarithmic-regression trend lines show distinct patterns of variability of between High-, Medium-, and Low- income countries. The High-Income countries show very strong correlation with its trendline, with correlation diminishing among Medium-Income countries and Low-Income countries. As countries become more affluent, their population numbers become a better indicator of vehicle ownership. The distinction between the different income categories is not exact as shown by the different colored samples.

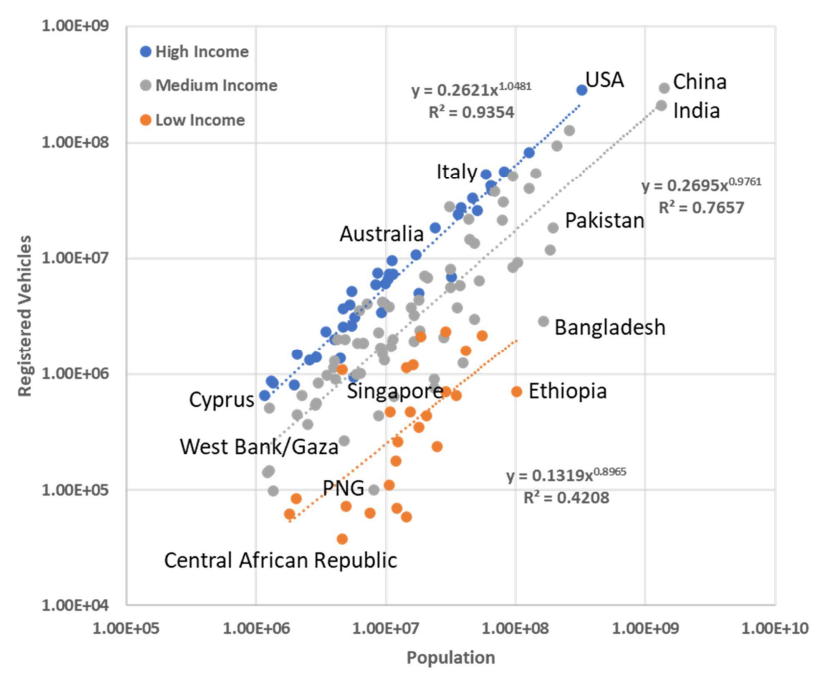

Figure 2. Distribution of population and registered vehicle by income.

Fatalities/10K vehicles and fatalities/100K population are illustrated as a function of income in Figures 3 and 4. The estimated fatalities $/ 10 \mathrm{~K}$ vehicle rate is disproportionately higher for Low Income countries than Middle and High Income counties.

The findings show that fatalities/10K vehicles and fatalities/100K population have a general trend of inversed relationship with income in the three income categories. Fatalities/100K population and fatalities/10K vehicles in low and middle-income countries are above the world's average (18.1 and 6.56, respectively), with a remarkable gap separating them from the high-income countries. The contributions of countries of each income category to the world's population, vehicles, and fatalities are shown in Figure 5. Low-income countries have higher fatality rates than those of the high-income countries regardless of having less vehicles per capita. Middle-income countries contribute the biggest share to fatalities: $80 \%$ of world's road deaths while comprising $76 \%$ of the world's total population and $60 \%$ of the world's total number of registered vehicles.

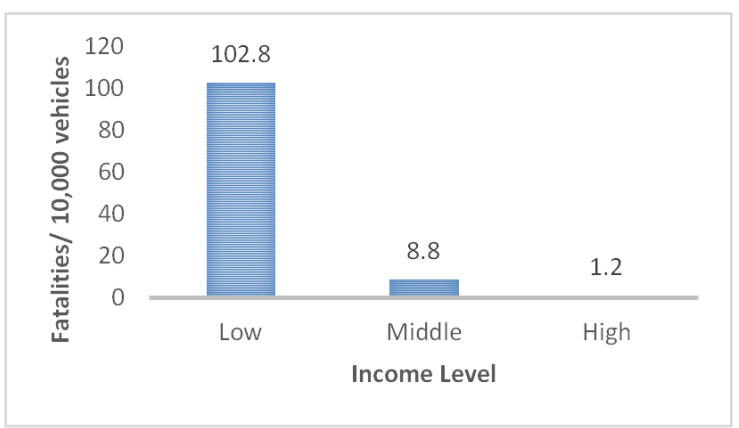

Figure 3. Estimated fatalities/10K vehicles for each income level.

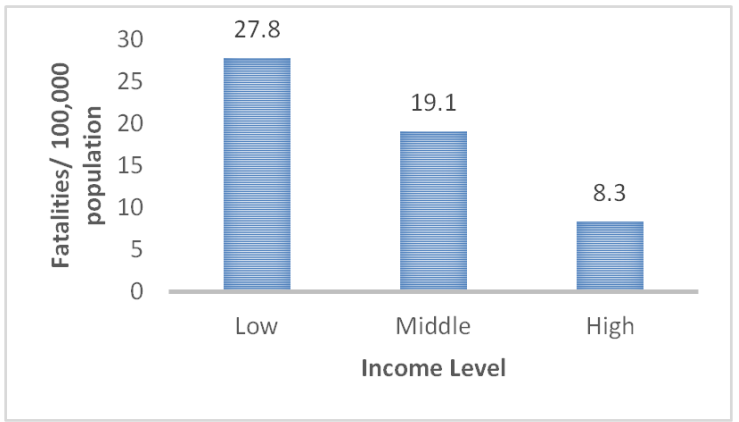

Figure 4. Estimated fatalities/100K population for each income level.

The global rate for road traffic deaths is 17.4 per $100 \mathrm{~K}$ population, however, as shown in Figure 3, there is great disparity by income, with rates more than twice as high those in low- and 
middle-income countries than in the world's high-income countries. A total of 104 countries have seen a rise in road traffic deaths since 2013 while 48 middle- and high- income countries have seen reductions in road fatalities. no reductions in the number of road deaths were observed in any low-income country.

In 2016, More than $90 \%$ of road traffic deaths occurred in low- and middle-income countries. While these countries also account for $84 \%$ of the world's population, they nevertheless bear a disproportionate number of deaths $(93 \%$ of the total world's road fatalities) relative to their level of motorization, as they account for approximately $61 \%$ of the world's registered vehicles [1]. This is shown in Figure 5.
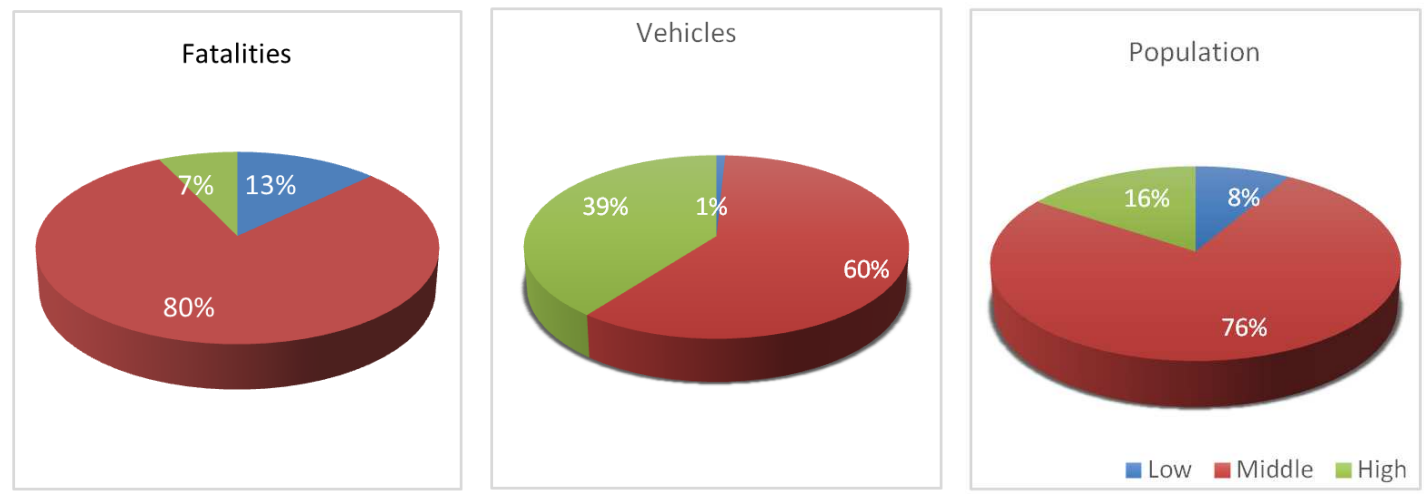

Figure 5. Population, road deaths and numbers of registered vehicles in low-, medium-and high-income countries.

\subsection{The Impact of Culture}

A map of cultures used in this study, as explained in the methodology, is shown in Figure 6. Cultures were compared in terms of fatalities/100K population (Figure 7) and fatalities/10K vehicles as shown in Figure 8 . The contributions of each culture towards the world's total population, number of fatalities, vehicles and vehicle ownership are shown in Figure 9.

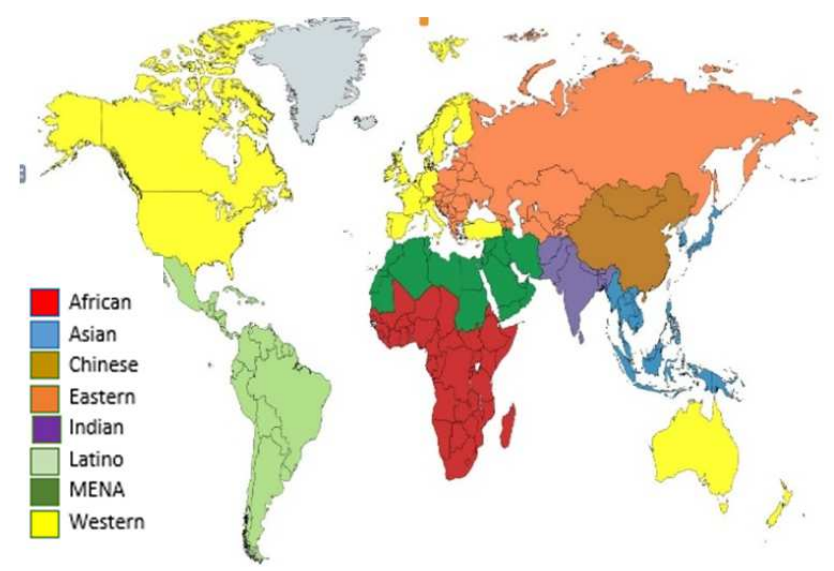

Figure 6. World's cultural map according to the classification of this study.

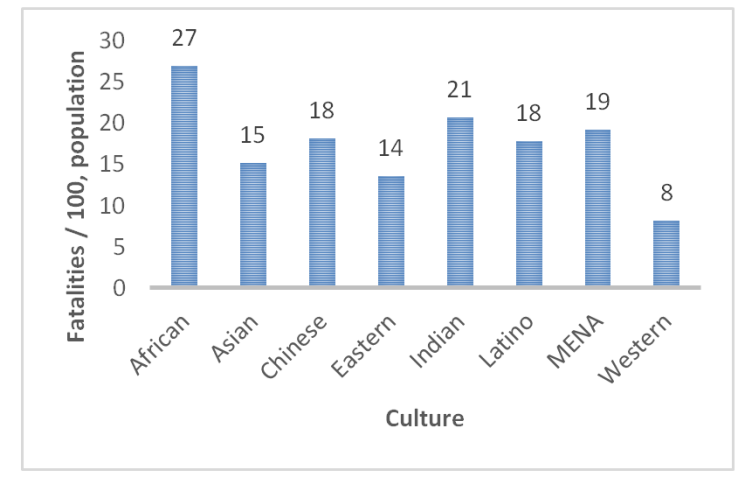

Figure 7. Estimated fatalities/100K population for each culture.

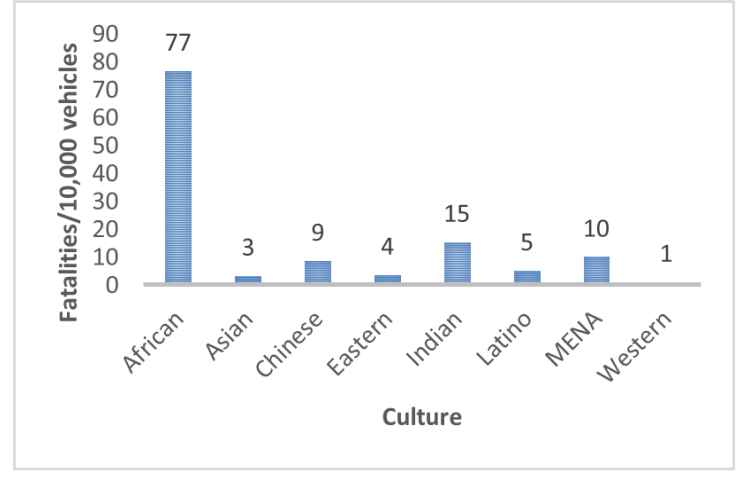

Figure 8. Estimated fatalities/10K vehicles for each culture.

The African culture has the highest fatalities/10K vehicles and fatalities $/ 100 \mathrm{~K}$ population. The Indian culture comes second in fatalities/10K vehicles while the MENA culture comes second in fatalities/100K population categories. The African, Chinese, Indian, Latino, and MENA cultures sustain fatality rates per population and vehicle greater than world's averages. Asian, Chinese, Latino, and Indian cultures have comparable fatalities rates yet vehicle access in the Latino culture is roughly three times less that of the Indian culture.

The African culture suffers more than fifty times the fatalities/10K vehicle compared to the Western culture even though the Western culture has 18 times the number of vehicles of the African culture. Western, Asian, and Eastern cultures have less fatalities/100K population and vehicles than the world's average. The African culture has similar fatalities per population to that of the MENA culture while the MENA culture has half the African's population and 1.5 times the number of vehicles. The MENA culture is ranked sixth in vehicles access, yet it comes second in fatalities $/ 100 \mathrm{~K}$ population and third in fatalities $/ 10 \mathrm{~K}$ of all cultures, despite its relatively small population. The African culture suffers higher fatalities per population and more than twice the fatalities $/ 10 \mathrm{~K}$ than the Indian culture despite being less than half the Indian culture population. 


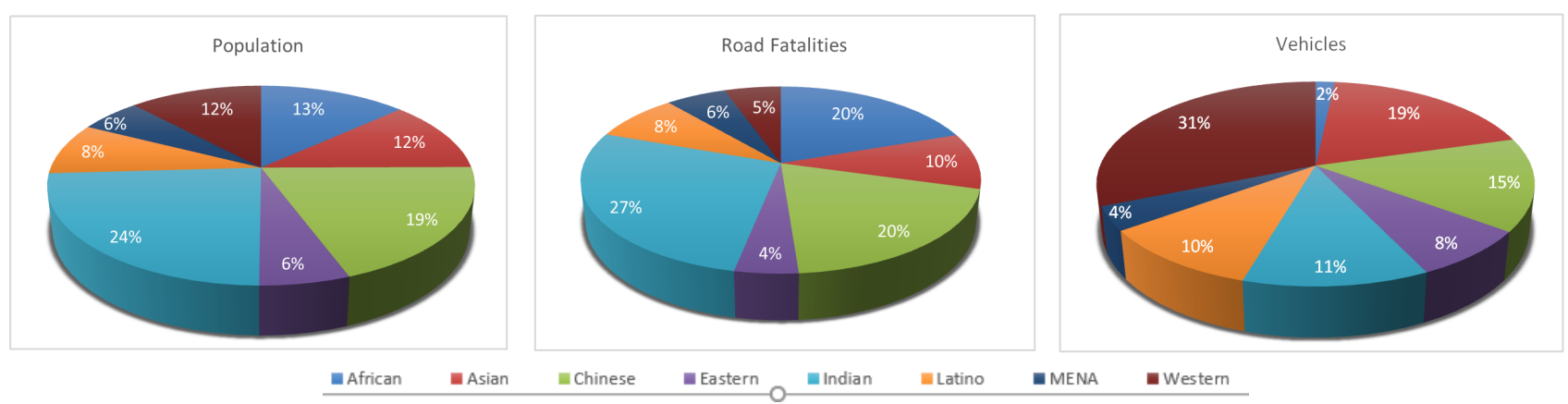

Figure 9. Population, road deaths and numbers of registered vehicles for each culture in the study.

The risk of a road traffic death varies significantly by region, with little change in the regional rates of death since 2010. The highest fatality rates are still in the African Region, while the European Region has a rate far below the global average ( 9.3 per 100000 population, relative to the global rate of 17.4). However, there continues to be a large disparity in rates within regions. For example, rates in some high-income countries in the Western Pacific Region (such as Australia) are among the lowest in the world, while some of the region's middle-income countries have rates above the global average at 24 per 100K. Similarly, high income countries generally have lower fatalities per capita rates than low- and middle-income countries. High-income countries in the Eastern Mediterranean Region have a higher fatalities per capita rate than those of their less-affluent neighbors in the region (22.4 compared to 19.7) and more than double the average rate of high-income countries globally (9.2). This suggests that in some of the more affluent Eastern Mediterranean countries, rapid economic development that has resulted in increased vehicles and road infrastructure construction has not been accompanied by sufficient investment in institutional capacity, nor in the interventions needed to cope with these changes and ensure that roads are safe. Section 2 of this report examines the extent to which interventions on key risk factors are adopted in different regions, while Section 3 considers the adoption of vehicle standards and infrastructure audits, all of which play an important role in determining overall road traffic fatality rates.

Overall, Western culture are the best safety performers with the lowest fatalities $/ 10 \mathrm{~K}$ vehicles and fatalities $/ 100 \mathrm{~K}$ population, although it has the highest vehicle ownership rate. The Asian culture has similar populations to the Western culture and half the vehicle density of the latter, yet suffers twice the fatalities $/ 100 \mathrm{~K}$ population and five times the fatalities $/ 10 \mathrm{~K}$ vehicles. Also, the Asian culture has more than twice the access to vehicles than the Chinese culture, yet it maintains about one-third of the fatalities $/ 10 \mathrm{~K}$ vehicles and lower fatalities/100K population. Despite the Chinese culture's higher vehicle ownership and lower population compared to the Indian culture, they contribute similarly to the world's total road fatalities.

The African and Chinese cultures contribute to the world's fatalities more than their contributions to the world's population while the Western culture contributes to the world's fatalities less than its contribution to the world's population. Other cultures contribute to the world's number of fatalities in nearly similar ratios to their contributions to the world's population. Contrary to the African, Indian, and Chinese cultures, the Asian, Eastern, and Western cultures contribute to the world's number of vehicles more than their contributions to the world's total fatalities.

The MENA and Eastern cultures are middle and high-income countries, while the Indian and the African cultures are low and middle-income countries. The Chinese and the Latino cultures are middle-income countries; the Western culture countries are high-income while the Asian culture countries have variable income levels.

Detailed of population, fatality rates and vehicle ownership are shown in Table 1.

Table 1. Population, fatalities, fatality rates and vehicles for each culture in the study.

\begin{tabular}{llllll}
\hline & Population & Estimated deaths & $\begin{array}{l}\text { Traffic Fatalities /100K } \\
\text { Population }\end{array}$ & $\begin{array}{l}\text { Number of registered } \\
\text { vehicles }\end{array}$ & $\begin{array}{l}\text { Traffic Fatalities } \\
\text { /10K Vehicles }\end{array}$ \\
\hline African & $963,714,223$ & 259,896 & 27.0 & $33,855,801$ & 76.8 \\
Asian & $848,776,516$ & 128,485 & 15.1 & $380,510,749$ & 3.4 \\
Chinese & $1,414,442,773$ & 256,679 & 18.1 & $295,535,994$ & 8.7 \\
Eastern & $421,429,218$ & 57,307 & 13.6 & $155,149,672$ & 3.7 \\
Indian & $1,743,965,220$ & 361,479 & 20.7 & $234,250,023$ & 15.4 \\
Latino & $613,690,719$ & 109,471 & 17.8 & $210,693,385$ & 5.2 \\
MENA & $401,297,884$ & 76,992 & 19.2 & $76,202,822$ & 10.1 \\
Western & $871,834,508$ & 71,539 & 8.2 & $630,327,021$ & 1.1 \\
\hline
\end{tabular}

Comparison of Traffic fatalities/100K population rates by culture are summarized in Table 2. The columns represent the culture being compared and the rows represent the culture being compared to. For example, Asian cultures are 1.11 times more traffic fatalities $/ 100 \mathrm{~K}$ population than Eastern cultures. A similar comparison is show in Table 3 for fatalities/10k 
vehicles. Red hues show comparisons greater than the reference culture while blue hues show comparisons below.
The darker the hue, the larger the variance between the two cultures.

Table 2. Comparison of traffic fatalities/100k population by cultures in the study.

\begin{tabular}{llllllll}
\hline & African & Asian & Chinese & Eastern & Indian & Latino & MENA \\
\hline African & 1.00 & 0.56 & 0.67 & 0.50 & 0.77 & 0.66 & 0.71 \\
Asian & 1.79 & 1.00 & 1.20 & 0.90 & 1.37 & 1.18 & 0.30 \\
Chinese & 1.49 & 0.83 & 1.00 & 0.75 & 1.14 & 0.98 & 1.27 \\
Eastern & 1.99 & 1.11 & 1.33 & 1.00 & 1.52 & 1.31 & 0.54 \\
Indian & 1.30 & 0.73 & 0.87 & 0.66 & 1.00 & 0.86 & 0.45 \\
Latino & 1.52 & 0.85 & 1.02 & 0.76 & 1.16 & 1.00 & 0.93 \\
MENA & 1.41 & 0.79 & 0.94 & 0.71 & 1.08 & 0.93 & 1.08 \\
Western & 3.29 & 1.84 & 2.21 & 1.66 & 2.52 & 0.40 & 2.17 \\
\hline
\end{tabular}

Table 3. Comparison of traffic fatalities/10k vehicles by cultures in the study.

\begin{tabular}{|c|c|c|c|c|c|c|c|c|}
\hline & African & Asian & Chinese & Eastern & Indian & Latino & MENA & Western \\
\hline African & 1.0 & 0.04 & 0.1 & 0.05 & 0.2 & 0.1 & 0.1 & 0.01 \\
\hline Asian & 22.6 & 1.0 & 2.6 & 1.1 & 4.5 & 1.5 & 3.0 & 0.3 \\
\hline Chinese & 8.8 & 0.4 & 1.0 & 0.4 & 1.8 & 0.6 & 1.2 & 0.1 \\
\hline Eastern & 20.8 & 0.9 & 2.4 & 1.0 & 4.2 & 1.4 & 2.7 & 0.3 \\
\hline Indian & 5.0 & 0.2 & 0.6 & 0.2 & 1.0 & 0.3 & 0.7 & 0.1 \\
\hline Latino & 14.8 & 0.7 & 1.7 & 0.7 & 3.0 & 1.0 & 1.9 & 0.2 \\
\hline MENA & 7.6 & 0.3 & 0.9 & 0.4 & 1.5 & 0.5 & 1.0 & 0.1 \\
\hline
\end{tabular}

\subsection{The Impact of Belief}

The world's religions mapped according to the classification used in this study are illustrated in Figure 10. The religion-based groups were compared in terms of fatalities/100K population (Figure 11) and fatalities/10K vehicles, as illustrated in Figure 12. Their contributions towards world's total population, number of fatalities, vehicles, and vehicle ownership are shown in Figure 13.

Indigenous believers suffer the highest fatalities $/ 10 \mathrm{~K}$ vehicles regardless of having the lowest vehicle ownership and lowest population. Muslims suffer the highest fatalities $/ 100 \mathrm{~K}$ population and the third highest fatalities/10K vehicles. Hindus, Muslims, Indigenous and Non-religious people have fatalities $/ 100 \mathrm{~K}$ population rates that are above the world's average. They also have significantly higher fatalities/10K vehicles than Christians and Buddhists. Buddhists have similar vehicle ownership and fatalities/10K vehicles compared to those of the Christians. Muslims and
Non-religious have similar shares of populations, fatalities $/ 10 \mathrm{~K}$ vehicles, fatalities/100K population and vehicles, they, also, contribute to the world's fatalities more than their contributions to the world's population while Buddhists, Hindus, and Indigenous contribute to both equally.

Christians are the best performers in terms of fatalities $/ 100 \mathrm{~K}$ population and fatalities/10K vehicles, although they have the highest access to vehicles. Christians own $56 \%$ of the world's vehicles and contribute to only $25 \%$ of the world's fatalities while their population contributes to $31 \%$ of the world's population. Christians and Buddhists are the only two groups whose fatalities/100K population and fatalities $/ 10 \mathrm{~K}$ vehicles are both below the world's averages and who contribute less to the world's fatalities than their contributions to the world's number of vehicles. Hindus and Indigenous believers live in low and middle-income countries, Judeo-Christians, Buddhists and Muslims live in low, middle and high-income countries, Non-religious countries are with the middle-income category.

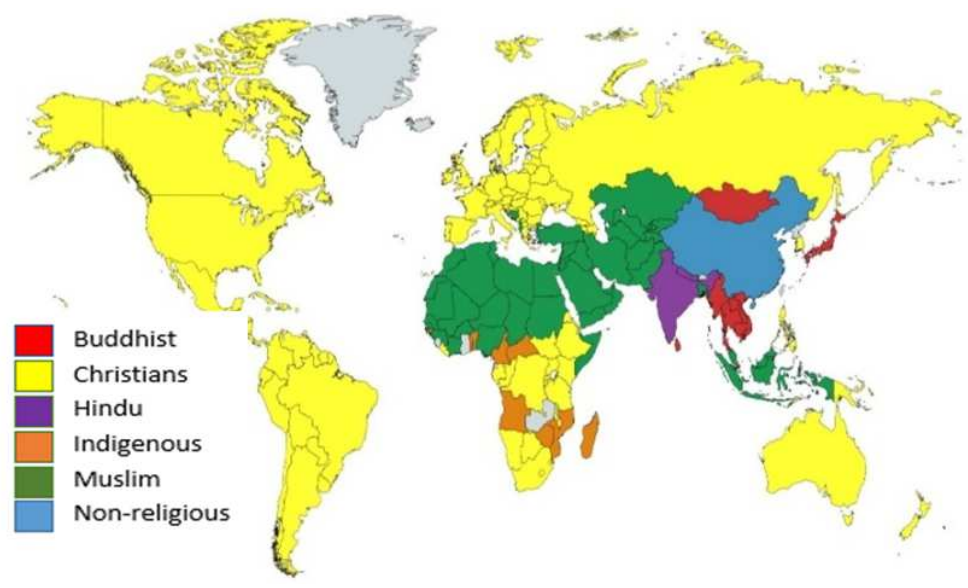

Figure 10. World religion map according to the classification of this study. 


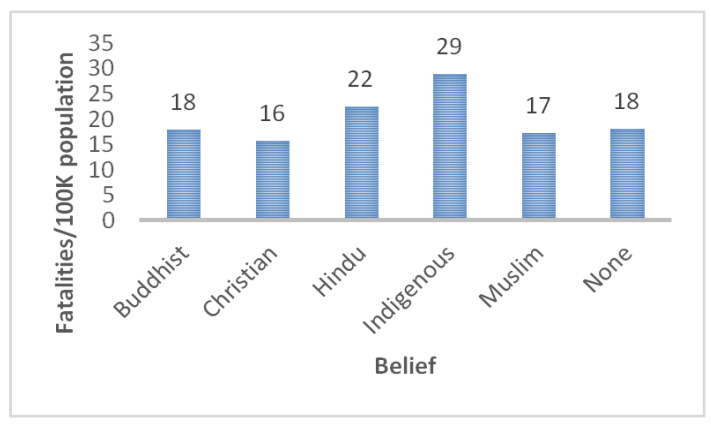

Figure 11. Estimated fatalities/100K population for each belief.

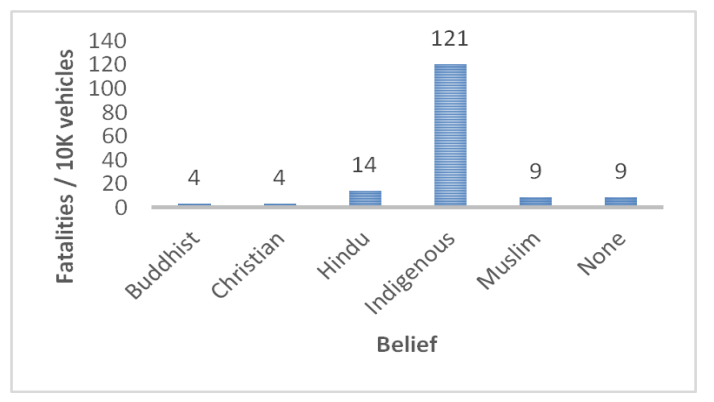

Figure 12. Estimated fatalities/10K vehicles for each belief.
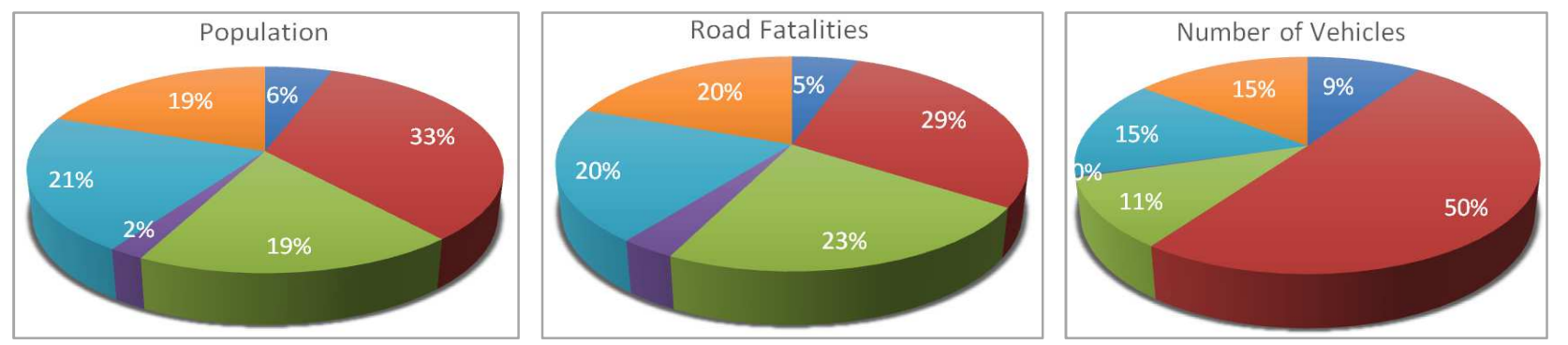

Buddhist

Christian

E Hindu

and.

Muslim

Non

Figure 13. Population, road deaths and numbers of registered vehicles for each belief.

\subsection{Income and Belief}

The subgroups of income, religion, and culture are compared in terms of fatalities/100K population and fatalities/10K vehicles. Figure 14 compares the means of fatalities/100K population of each income level and belief. It shows mitigation in fatalities $/ 100 \mathrm{~K}$ population as the income of the Muslims and Christians increases while there is a slight increase in fatalities when the income of Indigenous, Hindus, and Buddhists changes from low to middle. High-income Muslims have the highest fatalities/100K population in that income category. Non-religious, Indigenous, and Buddhists have similar fatalities/100K population within the middle-income category, Muslims and Hindus have the same trend with less fatalities.

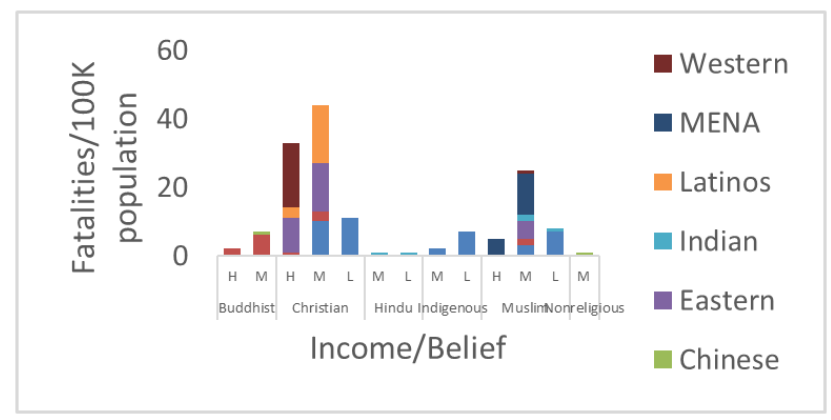

Figure 14. Fatalities/100K population versus income and belief.

Fatalities/10K vehicles as a function of income and belief are shown in Figure 15. Indigenous believers suffer the highest fatalities/10K vehicles in the low and middle-income categories, followed by low-income Judeo-Christians and middle-income Muslims. The middle-income Judeo-Christians have similar fatalities/ $10 \mathrm{~K}$ vehicles to those of the Hindus. Hindus and Buddhists countries have similar trends of fatalities $/ 10 \mathrm{~K}$ vehicles when moving from low to middle-income categories. High-income Judeo-Judeo-Christians, Muslims, and Buddhists perform similarly in terms of fatalities $/ 10 \mathrm{~K}$ vehicles where the Buddhists are the best performer. Muslims have much higher fatalities $/ 10 \mathrm{~K}$ vehicles than the Hindus in both low and middle-income categories.

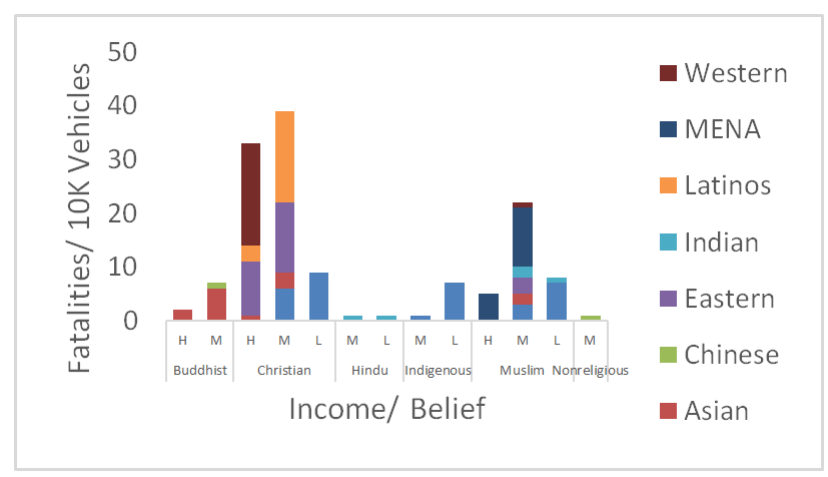

Figure 15. Fatalities/10K vehicles versus income and belief.

\subsection{Income and Culture}

The comparison of means of fatalities/100K population of different cultures based on their income, shown in Figure 16, shows a general trend of reduction in fatalities/100K population with the increase of income regardless of culture. However, there is not much change in fatalities $/ 100 \mathrm{~K}$ population with a change of income from low to 
middle-income within the African and Asian cultures. Latinos and MENA cultures sustain similar trends of fatalities/100K population when the income changes from middle to high. Fatalities/100K population in middle-income countries in the MENA, Latinos, Chinese, and African cultures are comparable and higher than those of other cultures within the middle-income category. Middle-income countries in Eastern and Indian cultures have similar fatalities/100K population rates. High-income countries in the Asian and Eastern cultures have similar fatalities $/ 100 \mathrm{~K}$ population where the highest fatalities/100K population in the high-income category belongs to the MENA culture.

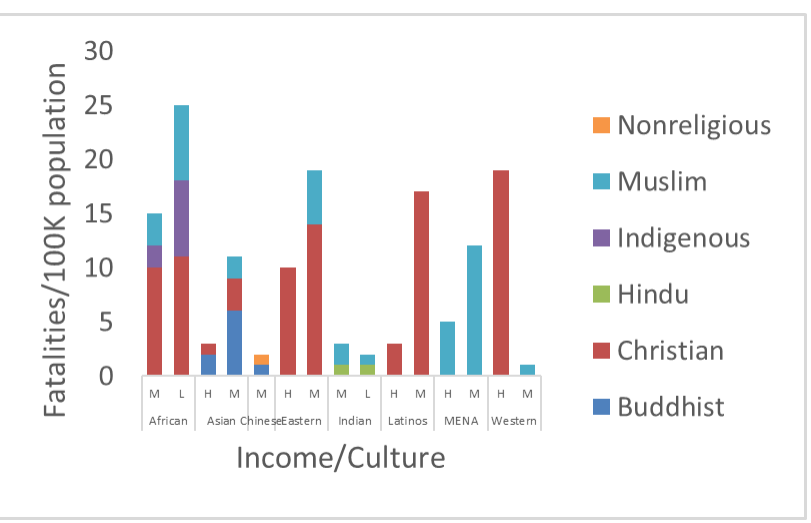

Figure 16. Fatalities/100K population versus income and culture.

A comparison of means of fatalities $/ 10 \mathrm{~K}$ vehicles in terms of income and culture, shown in Figure 17, clearly shows that the Low-income Africans have the highest fatalities $/ 10 \mathrm{~K}$ vehicles and are separated by a big gap from and middle-income countries within the African culture itself. Fatalities/10K vehicles are generally inversely proportional to income in most cultures. The Indian culture becomes second in fatalities/10K vehicles in the low-income category while the MENA culture suffers the highest fatalities $/ 10 \mathrm{~K}$ vehicles in the middle-income. The middle-income countries within the Chinese, Latinos, and Indian cultures have comparable fatalities/10K vehicles. Fatalities/10K vehicles of all high-income countries across all cultures are comparable.

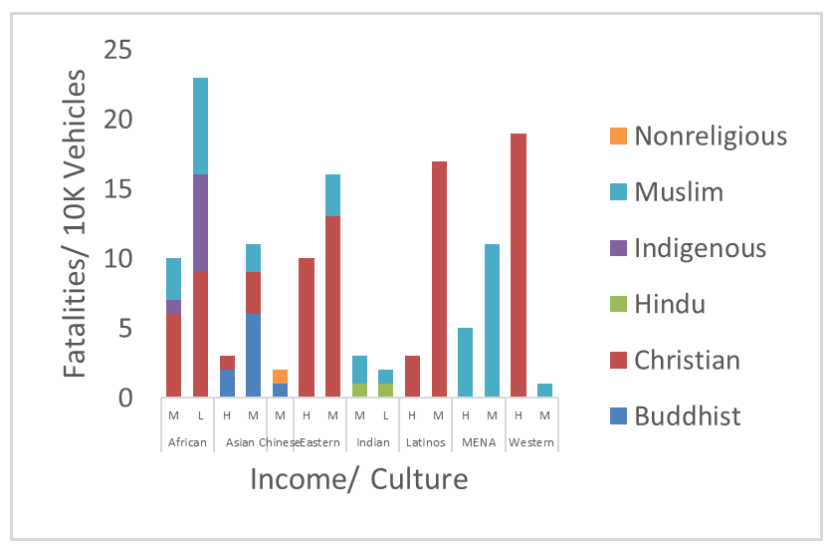

Figure 17. Fatalities/10K vehicles versus income and culture.

\section{Discussion}

\subsection{Income}

The fatalities/100K population and fatalities/10K vehicles were found to be inversely proportional to income regardless of religion and culture. Results show a big gap in the fatalities/10K vehicles across income levels. Low- and middle-income countries are highly populated with less motorization and so they may appear to underperform in terms of fatalities $/ 10 \mathrm{~K}$ vehicles.

The published level of income of each country may not reflect the real-world level of income of citizens of these countries due to unfair distribution of wealth. This is a common phenomenon in the low and middle income countries or countries with corrupt practices [26]. It is important to highlight that low- and middle-income countries have less road infrastructure and less safe vehicle fleet than those of high-income countries. Low-income is associated with other social values such as lower levels of education, poverty related cultures, and ability to accept or inherit different views without the capacity to test them. A connection was found between deprivation and high fatalities and casualties among low socioeconomic groups in India which in turn leads to more vulnerability and risky and adventurous driving [27].

Also, Low-income people may focus more on daily needs which make them less aware or careless about other issues that they think are less important, such as road safety. These issues are impacted by levels of income. When people's income increases, they tend to value their life more by the willingness to pay more for safer cars and their countries ability to afford better roads and roadside infrastructure that will improve road safety [28, 29].

Drivers in low-income countries have many risky and harmful driving habits such as poor observation of traffic laws and regulations [30]. They pay less attention to attitudes and perceived risk when committing their actions [31]. Drivers with a poor road safety culture were found to commit more errors and violations and were involved in more road crashes than their counterparts from the best performing countries where road safety culture is dominant among the majority of road users [32, 33]. Drivers in low-income countries reported more frequent crashes, compared to the number of cars and population [34] increasing the possibility of their involvement in a crash $[35,36]$ low-income countries do not spend a lot on safety as they have other priorities [37], similarly, people in low and high-income countries differ in their perception to safety due to the difference in their life priorities [38].

Road safety is affected by the socio-economic characteristics of local people [5], which is reflected in vehicle ownership rates, lifestyle, and exposure. Drivers who have an active lifestyle that requires more travel may have a higher probability of having road crashes [39]. Wealthier drivers were found to care less about being fined and were less safe drivers [40]. Educated drivers were found to be safer drivers [41]. 
The lower number of vehicles on roads means more people using other modes of transportation which may result in more people on roads in those countries with poor infrastructure and poor public transportation system, such as buses and minivans. This will lead to higher fatalities/vehicles and fatalities/population compared to other groups that have similar population but more access to vehicles. The inverse relationship of fatalities and vehicle ownership [39, 42, 43] is suggested to be attributed to collisions between vehicles rather than vehicles hitting pedestrians [5, 44].

The main findings confirm that economic progress alone does not automatically deliver better road safety performance, but transformational changes in the management of the road system along with ownership of the problem by multiple stakeholders are crucial to stabilize or reduce road crash fatalities and injuries [45]

\subsection{Culture}

The cultural context and perception of road safety determines the driving style of individuals by defining what is acceptable and what is not from both formal and informal rules [32]. What is considered a "normal" behavior is defined by the culture and the environment [12]. Individuals are a product of social influences [3] in which their social context acts as a navigation system [4]. The road is a social space where individuals from different social backgrounds meet and interact with other road users within their cultural framework [2]. Culture profoundly impacts the behavior of society members [46]. Safety culture has a major role in stimulating people to behave safely in general [47-52] and on roads in particular [53]. A positive correlation was found between socio-cultural, economic factors and low compliance with safe driving amongst driver in Dubai [54].

Fatalities/10K vehicles are generally inversely proportional to income in most cultures. Fatalities $/ 10 \mathrm{~K}$ vehicles of all high-income countries across all cultures are comparable. The African, Chinese, Indian, Latino, and MENA cultures sustain fatality rates per $100 \mathrm{~K}$ population and fatality rates per $10 \mathrm{~K}$ vehicles above the world's averages, most of these countries are low or middle-income countries. The Western, Asian, and Eastern cultures have fewer fatalities/100K population and fatalities $/ 10 \mathrm{~K}$ vehicles than the world's averages; most of these countries are middle or high-income countries. The similarity in fatalities $/ 100 \mathrm{~K}$ population between low and middle-income subgroups or middle and high-income subgroups may be attributed to the possibility that these countries have just emerged from being at that lower income level and they still retain that road safety culture from the former income level and that the road safety issues and road safety culture are still developing among people. This could be the case of African, Asian, Latinos, and MENA Eastern cultures with income subgroups.

Western culture is the best road safety performer amongst all cultures and is composed of high-income Christian countries. The Asian culture is the second-best performer regardless of the variance in income levels. African culture comprised of low- and middle-income countries, is the lowest performer amongst all cultural groups while the MENA culture is second worst performer. The MENA culture is composed of middle and high-income countries where the highest fatalities/100K population in the high-income category.

The relationship between vehicle ownership and fatalities is presented in the following examples. Asian cultures possess similar populations to Western cultures and half the vehicle density of the latter yet suffer twice the fatalities/100K population and five times the fatalities/10K vehicles. Chinese culture maintains higher vehicle ownership and lower population compared to the Indian culture, yet they contribute similarly to the world's total road fatalities. The three-fold more access to vehicles in the Latinos culture, compared to the Indian culture, resulted in one third of fatalities $/ 10 \mathrm{~K}$ vehicles compared to the Indian culture. This relationship may determine the types of crashes whether they are vehicle-human or vehicle-vehicle crashes and consequently the number of fatalities.

Differences in road safety among countries were found to be attributed to differences in the behavior of road users [5]. Nordfjærn, Jørgensen, and Rundmo [36] found that there is a cultural difference in the way drivers perceive road risks, their risk sensitivity, and their willingness to take risk. Driver's behaviors were reported to be predicted by their risk perception, risk sensitivity, willingness to take risk and their demographic characteristics, however, this model might not be applicable in some low-income countries [36]. Different cultures see behaviors differently, what is seen as a violation in some cultures is not considered the same in other cultures $[32,55]$. Attitudes might strongly predict behavior in one country (e.g. Norway) but not in another country (e.g., Ghana) [56]. Indeed, there are not many studies on traffic risk perception that compare two countries/cultures $[56,57]$ where most of them were carried out in developed industrial countries.

Risk perception is a relative concept that is affected by the driving environment. People view risk differently depending on their work type and nature, perception, education and awareness and their safety culture [56-61] Low and middle-income countries possess poor road infrastructure and pose hazardous environments to different road users. People who live in a hazardous traffic environment are exposed to more danger and severe consequences that will impact road safety [36]. For example, Sub-Saharan African drivers were found to be more willing to take more risks [36, 57] were more sensitive to hazards, and have a higher perception of road risks compared to their counterparts in Norway, India and Russia [36].

Road fatalities are an outcome of road crashes that often occur due to traffic violations [62-66]. Traffic violations are affected by social context $[8,32]$ or being a certain community member [64]. For example, aggressive violations are attributed to low social tolerance and to the aggressive interpersonal violations made a significant difference between drivers from northern Europe (e.g. Finland, The Netherland and Britain) and southern European (e.g. Turkey and Greece) 
and Middle Eastern drivers (e.g. Iran) [32, 33].

Aggressive violations could be explained by the propensity for interpersonal conflicts in some cultures due to competition on the road, the low respect for traffic law, untrusted enforcement, and less developed infrastructure [32]. The marginal difference in performance among cultures might be attributed to such cultural differences as well as being in different countries with different laws, driving environment, and enforcement. Different cultures may have different levels of accepting violations as normal behaviors. Drivers were found to be influenced by their social environment, other road users, social norms, formal and informal rules [4,67] social hierarchy, personal and social network [3], and Interpersonal network [68]. The degree of conformity decides the strength of cultural influence on the individual's behavior [69]. Social disapproval may influence drivers to refrain from committing violations [70]. Shinar [11] reported that some aggressive behaviors, such as running red lights and honking, are related to cultural norms.

There are some cultural factors that may affect driver's behaviors on the road. Hofstede, [71] identified the power distance, uncertainty avoidance, individualism and masculinity as dimensions that influence culture. High power-distance cultures normally have stricter rules on behaviors [72] for example, Japan and South Korea are viewed as more hierarchal and higher in power-distance [73] which may have a positive effect on the level of road safety in these countries. People living in cultures characterized with high uncertainty avoidance incline to support promising certainty beliefs as well as maintaining institutions protecting conformity [72], they try to evade uncertainty and so they will be more willing to take risks under stress [71]. Power distance and uncertainty avoidance are proportional with crashes while GNP and individualism are inversely proportional with crashes [37].

Culture has significant impact on people's daily lives when communicating with others and practicing their lifestyle. These values may not travel with them on roads and if not, the level of influence is unknown. Culture can be deemed to have marginal impact on road safety similar to that of beliefs. Violations, the main causes of crashes, were found to be cross-culture, belief, and country. For example, a strong relationship was found between aggressive violations and crashes in Finland and Iran despite different cultures and beliefs, traffic environments, enforcements and socio-economic characteristics [32].

\subsection{Belief}

Indigenous believers suffer the highest fatalities $/ 10 \mathrm{~K}$ vehicles regardless of having the lowest vehicle ownership and lowest population. This subgroup is represented within the African culture. Hindus, Muslims, Indigenous, and Non-religious people have closer fatalities/100K population that are above the world's average and are mainly in low and middle-income countries. Christians and Buddhists are the best performers with fatalities per vehicle and per inhabitants below the world's averages. These groups contribute less to the world's fatalities than their contributions to the world's number of vehicles. People in low and middle income countries were found more likely to be affected by superstitions due to their lower socio-economic status [74]. Fatalistic belief was thought to be higher in less educated societies [19] and the relationship between fatalism and poverty was suggested to be linked to culture and education [16].

There is no distinctive evidence of the effect of the belief on the level of road safety. For example, the best safety performer is the Western culture that comprises all Christian countries. However, these countries contain significant portions of agnostic people [75]. On the other hand, the least road safety performers are indigenous believers. The mix of different beliefs within the same country, the unknown level of religiosity, the ratio of religious people versus atheist/agnostic people, the unknown level of influence of belief on the daily life of individuals and the unknown level of correct understanding and interpreting of the belief by individuals make it hard to explore the effect of belief on people's perceptions, attitudes and behaviors, especially regarding road safety issues.

This study shows that different belief followers perform differently in different cultures and levels of income. For example, High-income Muslims (all in the MENA culture) have the highest fatalities $/ 100 \mathrm{~K}$ population in that income category. However, Muslims in the middle-income categories have fewer fatalities than Non-religious, Indigenous, and Buddhists. Middle-income Christians have similar fatalities $/ 10 \mathrm{~K}$ vehicles to those of the Hindus. Buddhists are the best performers in the high-income category in terms of fatalities $/ 10 \mathrm{~K}$ vehicles. This could be attributed to living in different countries and different driving environment rather than being attributed to belief.

\section{Findings Summary}

This study attempted to find out which of the income, belief, or culture of people that affect the level of road safety. There is a difference in the performance of fatalities/100K population and fatalities $/ 10 \mathrm{~K}$ vehicles across cultures and religions within each income category. A subgroup of different religions or cultures within the same income level may perform similarly or differently due to being in different countries. The country was the building block of the study's classification of income, culture, and belief.

The contributions of some countries to the world's road fatalities by more than their contributions to the world's number of vehicles could be attributed to having high density population, poor infrastructure, mix of people and vehicles on road without proper protection barriers [76] and the increase in the number of vehicles where people are not used to such volumes of traffic on roads yet. People in the high motorization countries travel more using vehicles where they become protected, they have better road and roadside infrastructure that are built to accommodate such traffic volumes as well as having better post-crash management 
system. Regardless of what high-income means in terms of safer roads, vehicles, and willingness to pay for safety, it is not the dominant player in safety on roads. Income has a tangible effect on road safety, but it is not the only player in this field.

In order to regress the influential player among income, culture, and belief in the area of road safety, each of group was analyzed separately. If income is considered as the dominant factor then there are some high-income groups that are underperforming (e.g. High-income MENA culture, Greece, Poland, Portugal and Croatia). If belief is considered as the dominant factor, Christians are the best performers, however some other believers outperform their Christian peers (e.g. Korea, Japan, Singapore and Brunei). If culture is considered as the dominant factor, Western culture is the best performer and is comprised of all high-income Christian countries. High-income Asian Buddhists, on average, outperform western countries. This confirms that none of the above three factors or a combination of them are dominant players in the area of road safety.

The main question this study explored was: What is the common factor between all high performing countries? The best performing countries, regardless of their culture and belief, are high-income countries that implement a road safety management system supported by consistent and lasting enforcement of the traffic law that was well known as the way of improving safety [39, 77]. These are the rule of law countries that had the political will that is essential for any road safety management program [78-81].

\section{Conclusion}

Culture and belief were found to have marginal impacts on road safety. However, any road safety strategy should take culture and belief of the people into account when carrying out road safety countermeasures in order to produce the desired results $[31,68,82]$ and to gain the social acceptance [52, 83-85]. Different cultures have different perceptions to road risks [86] and traffic policy makers should not assume traffic laws are pan-cultures [32]. It was reported that people who resist road safety policy measures have been found to perform well in terms of road safety [87].

Traffic safety countermeasures that succeeded in developed countries may not always succeed in developing countries due to the difference in cultural and socio-economic factors $[36,88]$.

The rule of law that is consistent, fair, continuously enforced, and built on the right strategy that takes the belief and culture of people into account, are the keys for safer roads. There must be a political will to improve road safety by building the right road safety management system that will produce positive driving behaviors and a robust road safety culture that is consistent with local people. Road safety authorities should exchange experiences in road safety, especially those that are related to cultures and belief due to the overlapping of these factors across countries.

\section{Limitations of the Study}

This study has limitations due to the fuzzy lines of culture and religion classifications used and the data availability. The political and legal system, roads infrastructure, vehicle fleet, detailed socio-economic status of the people, road law enforcement level and local environmental conditions are not present in this paper; they vary by country and may play a significant role in road safety. In this paper, UN data was used from 2018 where the data has limited numbers of countries with the needed information.

The question of what contributes more to road trauma is not completely answered due to the overlapping of cultures and religions within the same country or across countries that have different levels of income. A variety of cultures and religions can exist together within one country may have separate as well as interacting effects on road safety. The level of adherence to culture or the level of religiosity is also unknown. Since we do not have exact details about the socio-economic status of people within the income, culture or religions subcategory, or even within the same country, we are unable to correlate the road safety level to their socio-economic status, culture or belief precisely. There are some physical environmental factors that can be possible contributors to road trauma such as arid environment, high temperatures, nature, and geography of the land. These issues were not investigated in this study.

The risk of a road traffic death varies significantly by region, and there has been little change in the regional rates of death since 2010. The highest rates are still in the African Region, while the European Region has a rate far below the global average (9.3 per 100000 population, relative to the global rate of 17.4 per 100000 population). However, there continues to be a large disparity in rates within regions. For example, rates in some of the high-income countries in the Western Pacific Region (such as Australia) are among the lowest in the world, while some of the region's middle-income countries have rates high above the global average at 24 per 100 000. Similarly, while high income countries generally have lower rates than low- and middle-income countries, high-income countries in the Eastern Mediterranean Region have a higher rate than those of their less-affluent neighbors in the region (22.4 compared to 19.7) and more than double the average rate of high-income countries globally (9.2). This suggests that in some of the more affluent Eastern Mediterranean countries, rapid economic development that has resulted in increased motorization and road infrastructure construction has not been accompanied by sufficient investment in institutional capacity, nor in the interventions needed to cope with these changes and ensure that roads are safe. Section 2 of this research examines the extent to which interventions on key risk factors are adopted in different regions, while Section 3 considers the adoption of vehicle standards and infrastructure audits, all of which play an important role in determining overall road traffic fatality rates. 


\section{References}

[1] WHO 2018. Global status report on road safety 2018: Geneva: World Health Organization; License: CC BY-NC-SA 3.0 IGO. [Online]. Available: Global status report on road safety 2018 (who.int).

[2] Engel, R. 2009. Social and Cultural Factors. France Traffic Accident Causation in Europe (TRACE).

[3] Fleiter, J. J., Watson, B. C., Lennon, A. J., King, M. J. \& Shi, K. 2011. Social influences on drivers in China. Journal of the Australasian College of Road Safety, 22, 7.

[4] Zaidel, D. M. 1992. A modeling perspective on the culture of driving. Accident Analysis and Prevention, 24, 585-597.

[5] Bener, A. \& Crundall, D. 2005. Road traffic accidents in the United Arab Emirates compared to Western countries. Advances in Transportation Studies an international Journal Section A, 6 .

[6] Taubman-Ben-Ari, O. \& Yehiel, D. 2012. Driving styles and their associations with personality and motivation. Accident Analysis and Prevention, 45, 416-422.

[7] Koushki, P. A. \& Ali, M. A. 2003. An analysis of pedestrian accidents in Kuwait. Kuwait Jornal of Science and Engineering 30, 139-152.

[8] Reason, J., Campbell, K., Baxter, J., Stradling, S. \& Manstead, A. 1990. Errors and violations on the roads: a real distinction? Ergonomics, 33, 1315-1332

[9] Chliaoutakis, J. E., Koukouli, S., Lajunen, T. \& Tzamalouka, G. 2005. Lifestyle traits as predictors of driving behaviour in urban areas of Greece. Transportation Research Part F: Traffic Psychology and Behaviour, 8, 413-428.

[10] Chliaoutakis, J. E., Darviri, C. \& Demakakos, P. T. 1999. The impact of young drivers' lifestyle on their road traffic accident risk in greater Athens area. Accident Analysis \& Prevention, 31, 771-780.

[11] Shinar, D. 1998. Aggressive driving: the contribution of the drivers and the situation. Transportation research. Part F, Traffic psychology and behaviour., 1F.

[12] Özkan, T., Lajunen, T., Parker, D., Sumer, N. \& Summala, H. 2010. Symmetric Relationship Between Self and Others in Aggressive Driving Across Gender and Countries. Traffic Injury Prevention, 11, 228-239.

[13] Pravhakar, T., Lee, S. \& Job, R. Risk Taking, optimism bias and risk utility in young drivers. In: ST.JOHN, L., ed. The Road Safety Research and Enforcement Conference., 1996 Sydney, NSW. Roads \& Traffic Authority of NSW, 61-68.

[14] Hilton, J. 2006. Race and Ethnicity in Fatal Motor Vehicle Traffic Crashes 1999 - 2004. Washington, DC: National Center for Statistics and Analysis, National Highway Traffic Safety Administration.

[15] Kouabenan, D. R. 2009. Role of beliefs in accident and risk analysis and prevention. Safety Science, 47, 767-776.

[16] Kayani, A., King, M. J. \& Fleiter, J. J. 2011. Fatalism and Road Safety in Developing Countries, with a Focus on Pakistan. Journal of the Australasian College of Road Safety, 22, 41-47.
[17] Kayani, A., King, M. J. \& Fleiter, J. J. 2012. Fatalism and its implications for risky road use and receptiveness to safety messages: a qualitative investigation in Pakistan. Health education research, 27, 1043-54.

[18] Kayani, A., Fleiter, J. J. \& King, M. J. 2013. Under-reporting of road crashes in Pakistan and the role of fate. Traffic Injury Prevention.

[19] Girasek, D. C. 1999. How members of the public interpret the word accident. Injury Prevention, 5, 19-25.

[20] Barss, P., Al-Obthani, M., Al-Hammadi, A., Al-Shamsi, H., El-Sadig, M. \& Grivna, M. 2008. Prevalence and issues in non-use of safety belts and child restraints in a high-income developing country: Lessons for the future. Traffic Inj. Prev. Traffic Injury Prevention, 9, 256-263.

[21] King, M. J. \& King, J. A. 2006. Do high status people in an hierarchical society know how ordinary people attribute road crash causation? A case study from Thailand [Online]. Centre for Social Change Research, School of Humanities and Human Services, QUT.

[22] Kouabenan, D. R. 1998. Beliefs and the Perception of Risks and Accidents. Risk analysis: an official publication of the Society for Risk Analysis., 18, 243.

[23] Norenzayan, A. \& Lee, A. 2010. It Was Meant to Happen: Explaining Cultural Variations in Fate Attributions. Journal of Personality and Social Psychology, 98, 702-720.

[24] Acevedo, G. A. 2008. Islamic fatalism and the clash of civilizations: An appraisal of a contentious and dubious theory. Social Forces, 86, 1711-1752.

[25] CIA Fact book https://www.cia.gov/library/publications/the-world-factbook/.

[26] Perkins, J. 2004. Confessions of an economic hitman, San Francisco, Berret-Koehler Publishers.

[27] Chinnappa, N. D. (January 01, 2021). Impact of socio-economic profiles on public health crisis of road traffic accidents: A qualitative study from South India. Clinical Epidemiology and Global Health, 9, 7-11.

[28] Andersson, H., Hammitt, J., Lindberg, G., \& Sundström, K. (2011). Willingness to pay and sensitivity to time framing: A theoretical analysis and an application on car safety. Toulouse.

[29] Austroads 2015 Social Costs of Road Crashes in Australia: The Case for Willingness-to-pay Values for Road Safety. Research Report AP-R438-15 Sydney, Australia.

[30] Bener, A., Jadaan, K. S., Al-Mulla, A. A., Bensiali, A. K. \& Abu-Zidan, F. M. 2003. Strategy to improve road safety in developing countries. Saudi medical journal, 24, 603-608.

[31] Rundmo, T., Granskaya, J. \& Klempe, H. 2012. Traffic culture as symbol exchange - A cross-country comparison of Russia and Norway. Safety Science, 50, 1261-1267.

[32] Özkan, T., Lajunen, T., Chliaoutakis, J. E., Parker, D. \& Summala, H. 2006a. Cross-cultural differences in driving behaviours: A comparison of six countries. Transportation Research Part F: Psychology and Behaviour, 9, 227-242.

[33] Özkan, T., Lajunen, T., Chliaoutakis, J. E., Parker, D. \& Summala, H. 2006b. Cross-cultural differences in driving skills: A comparison of six countries. Accident Analysis and Prevention, 38, 1011-1018. 
[34] Lagarde, E. 2007. Road traffic injury is an escalating burden in Africa and deserves proportionate research efforts. PLoS medicine, 4

[35] Nantulya, V. M. \& Reich, M. R. 2002. The neglected epidemic: road traffic injuries in developing countries. British Medical Journal, 324, 1139-1141.

[36] Nordfjærn, T., Jørgensen, S. \& Rundmo, T. 2011. A cross-cultural comparison of road traffic risk perceptions, attitudes towards traffic safety and driver behaviour. Journal of Risk Research, 14, 657-684.

[37] Özkan, T. \& Lajunen, T. 2007. The role of personality, culture, and economy in unintentional fatalities: An aggregated level analysis. Personality and Individual Differences, 43, 519-530.

[38] Affeltranger, B. \& Thomasson., F. 2005. 2005. Accidents and poverty in the developing world: A review of current research and thinking. Sweden: Report commissioned by Räddingsverket, the Swedish Rescue Services Agency.

[39] Koushki, P., Bustan, M. \& Kartam, N. 2003. Impact of safety belt use on road accident injury and injury type in Kuwait. Accident Analysis \& Prevention, 35, 237-241.

[40] Al-Madani, H. 2004. Drivers' Speed Citation Involvement in Five Arabian Gulf Countries. eng Journal of King Abdulaziz University-Engineering Sciences, 15, 49-62

[41] Peer, E. 2011. The time-saving bias, speed choices and driving behavior. Transportation Research Part F: Psychology and Behaviour, 14, 543-554.

[42] Jadaan, K. S. 1988. Traffic safety in Gulf countries with special reference to Kuwait. Transport reviews., 8.

[43] Bener, A., Lajunen, T., Ozkan, T. \& Haigney, D. 2006. The effect of mobile phone use on driving style and driving skills. International Journal of Crashworthiness, 11, 459-465.

[44] Abbas, A., Hefny, A. \& Abu-Zidan, F. 2011. Seatbelt compliance and mortality in the Gulf Cooperation Council countries in comparison with other high-income countries. Annals of Saudi Medicine, 31, 347-350.

[45] Dahdah, Said; Bose, Dipan. 2013. Road Traffic Injuries: A Public Health Crisis in MENA. MENA knowledge and learning quick notes series; no. 111. World Bank, Washington, DC

https://openknowledge.worldbank.org/handle/10986/20558 License: CC BY 3.0 IGO.”

[46] Mcneely, C. L. \& Gifford, J. L. 2007. Effecting a traffic safety culture: Lessons from cultural change initiatives. Washington, DC: AAA Foundation for Traffic Safety.

[47] Cooper, D. 2000. Towards a model of safety culture. Safety science., 36, 111-136.

[48] Cooper, D. 1998. Improving safety culture: a practical guide, Chichester; New York, Wiley.

[49] Cox, S. \& Cox, T. 1991. The structure of employee attitudes to safety: A European example. Work \& Stress, 5, 93 - 106.

[50] Dejoy, D. M. 2005. Behavior change versus culture change: Divergent approaches to managing workplace safety. Safety science., 43, 105-129.

[51] Gadd, S. \& Collins, A. M. 2002. Safety culture: a review of the literature, Health and Safety Laboratory.
[52] Howard, E. \& Sweatman, P. 2007. Road safety culture development for substantial road trauma reduction: can the experience of the state of Victoria, Australia, be applied to achieve road safety improvement in North America?

[53] Wiegmann, D. A., Thaden, T. L. V. \& Gibbons, A. M. 2007. A review of safety culture theory and its potential application to traffic safety. Washington, DC: AAA Foundation for Traffic Safety.

[54] Tanvir, S., Habib, N. Z., Walker, G. H., \& AHFE International Conference on Human Factors in Transportation, 2018. (January 01, 2019). A Qualitative Investigation of Professional Driver Behavior Due to Socio-Economic, Cultural, Religious Factors and Its Impact on Dubai Road Safety. Advances in Intelligent Systems and Computing, 786, 764-775.

[55] Lajunen, T., Parker, D. \& Summala, H. 2004. The Manchester Driver Behaviour Questionnaire: a cross-cultural study. Accident Analysis \&amp; Prevention, 36, 231-238.

[56] Nordfjaern, T. \& Rundmo, T. 2009. Perceptions of traffic risk in an industrialised and a developing country. Transportation Research Part F: Psychology and Behaviour, 12, 91-98.

[57] Lund, I. O. \& Rundmo, T. 2009. Cross-cultural comparisons of traffic safety, risk perception, attitudes and behaviour. Safety Science, 47, 547-553.

[58] Sjöberg, L. 2000. Factors in Risk Perception. Risk Analysis, 20, $1-12$.

[59] Sjöberg, L., Rundmo, T. \& Moen, B. E. 2004. Explaining Risk Perception: An Evaluation of the Psychometric Paradigm in Risk Perception Research, Rotunde.

[60] Åstrøm, A. N. 2006. Perceived susceptibility to and perceived causes of road traffic injuries in an urban and rural area of Tanzania. Accident analysis and prevention., 38, 54-62.

[61] Boholm, A. 1998. Comparative studies of risk perception: a review of twenty years of research. Journal of Risk Research, 1, 135-163.

[62] Parker, D., Stradling, S. G., Manstead, A. S. R. \& Reason, J. T. 1995. Driving errors, driving violations and accident involvement. Ergonomics, Vol. 38, No. 5, 1995, p. 1036-1048.

[63] Al-Balbissi, A. H. 2003. Role of gender in road accidents. Traffic injury prevention., 4, 64-73.

[64] Parker, D. \& Stradling, S. 2004. Influencing driver attitudes and behaviour. The Seventh SPE International Conference on Health, Safety, and Environment in Oil and Gas Exploration and Production. Calgary, Canada.

[65] Stanojevic, P., Jovanovic, D. \& Lajunen, T. 2013. Influence of traffic enforcement on the attitudes and behavior of drivers. Accident Analaysis and Prevention, 53, 29-38.

[66] Kontogiannis, T., Kossiavelou, Z. \& Marmaras, N. 2002. Self-reports of aberrant behaviour on the roads: errors and violations in a sample of Greek drivers. Accident Analysis \& Prevention, 34, 381-399.

[67] Björklund, G. 2005. Driver interaction: informal rules, irritation and aggressive behaviour. Ph. D., Acta Universitatis Upsaliensis.

[68] Xie, C.-Q. \& Parker, D. 2002. A social psychological approach to driving violations in two Chinese cities. Transportation Research Part F: Traffic Psychology and Behaviour, 5, 293-308. 
[69] Berry, J. W., Poortinga, Y. H., Segall, M. H. \& Dasen, P. R. 2002. Cross-cultural psychology: research and applications, Cambridge [England]; New York, Cambridge University Press.

[70] Parker, D., Reason, J. T., Stradling, S. G. \& Manstead, A. S. R. 1992. Determinants of intention to commit driving violations. Accident Analysis and Prevention, Vol. 24, No. 2, April 1992, p. $117-131$.

[71] Hofstede, G. H. 2001. Culture's consequences: comparing values, behaviors, institutions, and organizations across nations, Thousand Oaks, Calif., Sage Publications.

[72] Shiraev, E. \& Levy, D. A. 2010. Cross-cultural psychology: critical thinking and contemporary applications, Boston, MA, Pearson/Allyn and Bacon.

[73] Matsumoto, D. 2007. Individual and Cultural Differences On Status Differentiation: The Status Differentiation Scale. Journal of Cross-Cultural Psychology, 38, 413-431.

[74] Scanlon, T. J. 1993. Is Friday the 13th bad for your health? British medical journal, 307, 1584-1586.

[75] Chapmans, T. 2013. The Largest Atheist / Agnostic Populations [Online]. http://www.thechapmans.nl/news/Atheist.pdf.

[76] O'Neill, B. \& Mohan, D. 2002. Reducing motor vehicle crash deaths and injuries in newly motorising countries. British Biomedical Journal, 324, 1142-1144.

[77] Bener, A., Al Humoud, S. M. Q., Price, P., Azhar, A., Khalid, M K., Rysavy, M. \& Crundall, D. 2007. The effect of seatbelt legislation on hospital admissions with road traffic injuries in an oil-rich, fast-developing country. International Journal of Injury Control and Safety Promotion, 14, 103-107.

[78] WHO 2004. World Report on Road Traffic Injury Prevention. World Health Organization (WHO).
[79] Bliss, T. \& Breen, J. 2009. Implementing the Recommendations of the World Report on Road Traffic Injury Prevention: Country Guidelines for the Conduct of Road Safety Management Capacity Reviews and the Specifi cation of Lead Agency Reforms, Investment Strategies and Safe System Projects. World Bank Global Road Safety Facility.

[80] Toroyan, T. \& Peden, M. M. 2007. Youth and road safety [Online]. Geneva, Switzerland: World Health Organization.

[81] Shinar, D. 2007. Traffic safety and human behavior, Amsterdam; London, Elsevier.

[82] Koushki, P. A. \& Ali, S. Y. 1993. Pedestrian characteristics and the promotion of walking in Kuwait City center. Transportation research record.

[83] Blais, E. \& Dupont, B. 2005. Assessing the Capability of Intensive Police Programmes to Prevent Severe Road Accidents A Systematic Review. The British Journal of Criminology, 45, 914-937.

[84] Porter, B. E. 2011. Chapter 31 - Enforcement. In: BRYAN, E. P. (ed.) Handbook of Traffic Psychology. San Diego: Academic Press.

[85] Ofosu, J. B., Abouammoh, A. M. \& Bener, A. 1988. A study of road traffic accidents in Saudi Arabia. Accident analysis and prevention., 20.

[86] Lam, L. T. 2005. Parental risk perceptions of childhood pedestrian road safety: A cross cultural comparison. Journal of Safety Research, 36, 181-187.

[87] Van, B. W., Schachner, M., Sgarra, V., \& Christie, N. (January 01, 2020). The association between national culture, road safety performance and support for policy measures. Iatss Research, 44, 3, 197-211.

[88] Bank, A. D. 1998. Road safety guidelines for the Asian and Pacific region, Manila, Asian Development Bank. 